\section{FOR EVERY BUDGET WITHOUT COMPROMISE}

Classic Dental Cabinetry (CDC) can supply 'off-the-shelf' solutions for worktops, sinks and taps tackling the major areas of compliance. Alternatively they can provide full bespoke solutions suitable for the smallest spaces to complete new-builds.

The CDC range features quality post-formed worktops, PVC-edged doors and carcase fronts, quality sinks and mixer taps - all designed on a bespoke basis. CDC can include split height designs for superior ergonomics, custom instrument drawers which lock in the open position, custom suction motor housings, CVS tip support modules, tray storage and single cabinetry runs for smaller surgeries.

CDC is extremely competitively priced and available either supply only or with full installation support. Like the remainder of their Classic Dental range it is designed to suit every budget without compromising on form or function.

For further information email info@ classicdentalcabinetry. co.uk or visit www. classicdentalcabinetry.co.uk.

\section{THE ONLY THREE-AXIS BITE REGISTRATION GAUGE}

Kosmo Technologies has developed the Andra Gauge, the only three-axis bite registration gauge that quickly and accurately provides the dental lab with the exact location of the construction dental bite. This device delivers the best fitting oral appliance or even fundamental dental bites for crowns, implants, sleep and TMD/TMJ appliances and splints as well as all other orthodontics.

The Andra Gauge can reproduce and hold the position of the mandible in relation to the maxilla in three dimensions. This accuracy and ease-of-use allows dentists to quickly and easily capture the optimal position of the mandible. Once sent to the lab, the Andra Gauge simply describes the position to the oral appliance fabricator, allowing the lab to create an oral appliance that is more comfortable and helpful to the patient.

Typically, dental labs can experience an $80 \%$ failure rate due to miscommunication from the construction bite. This leaves the dental lab to make assumptions

\section{LIOUID LENS TECHNOLOGY}

Carestream Dental has been overwhelmed by the response to the Kodak 1500 Intraoral camera.

A lightweight, ergonomically designed and easily manoeuvred device, the Kodak 1500 camera offers dental practitioners fantastic image quality, thanks to its pioneering liquid lens technology.

Focusing like the human eye, the Kodak 1500 camera captures high-resolution images and video with undesired light reflection eliminated by the automatic adjustment to lighting conditions.

The user can take still portraits, full arch, intraoral and macro views with LEDs for optimal that should not be made, especially when millimetres matter. The Andra Gauge allows the practitioner to clearly communicate in three dimensions the location of the mandible in relationship to the maxilla including the critical locations of the midline and vertical positions of the bite.

For further details as well as video instructions for use, visit http://AndraGauge.com.

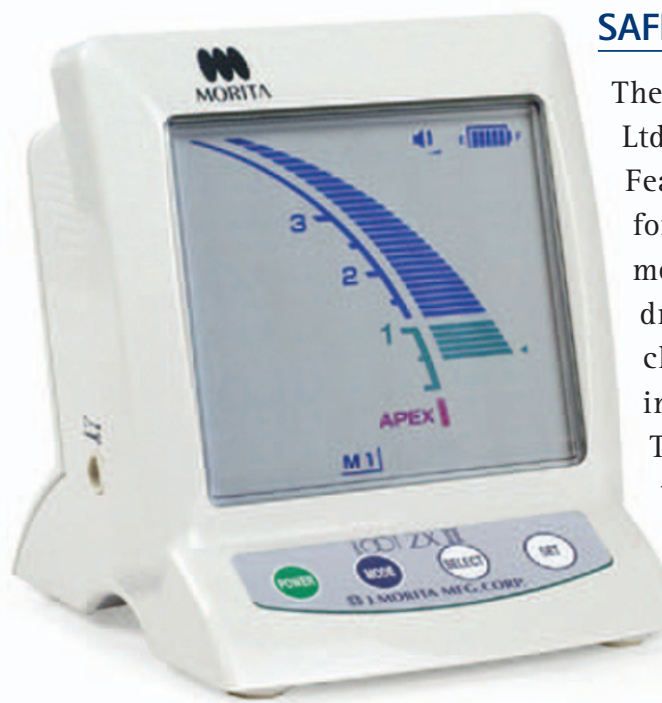

\section{SAFE ROOT CANAL PREPARATION}

The Morita Root ZX apex locator from QED Ltd is light, tough and easily transported. Featuring a colour Liquid Crystal Display for a clear view, the Root ZX makes accurate measurements whether the canal is wet or dry. The file position and movement are clearly shown in real time with easy to read increments for high precision measurements. The display instantly changes to green as the file approaches the apex. File position is also indicated by the audible signal for additional precision.

The Root ZX can be upgraded by simply attaching the Dentaport Motor Module. This illumination of even the hardestto-see areas.

The Kodak 1500 camera also uses the latest WiFi technology for improved freedom of movement around the chair and allows for ease of sharing with other clinicians, affording efficient workflow. The information can be directly transferred and displayed on either a computer or video monitor, making patient interaction more dynamic. www.practiceworks.co.uk enables clinicians to prepare the canals while simultaneously measuring the canal depth.

Incorporating auto start and stop, auto torque reverse, auto apical reverse/stop and auto apical slow down features, it facilitates quick, accurate and safe root canal preparation.

Both items are highlighted in the QED Catalogue and featured on www.qedendo.co.uk. For further information telephone 01733404999 or email sales@ qedendo.co.uk. 